\title{
THE EFFECT OF SURFACE TREATMENTS ON MICROHARDNESS AND FLEXURE STRENGTH OF RESIN CERAMICS.
}

\author{
Mahmoud El-Said Ahmed Abd El-Aziz*, Mohamed Shokry Ali*, Adel Mohamed Shaaban***
}

\begin{abstract}
Objective: The objective of this study was intended for evaluation the effect of different surface treatments on microhardness and flexural strength of two types of resin ceramics. Materials and Methods: A total number of 140 samples were used in this study (70 samples for each test). This samples were divided into two equal groups according to materials (Vita Enamic [ENA] and Lava Ultimate [LVU]), then each group was subdivided according surface treatments into five subgroups Gr 1; no surface treatment (control), Gr 2; alumina particles with size $(50 \mu \mathrm{m})$ for sandblasting, Gr 3; alumina particles with size (110 $\mu \mathrm{m})$ for sandblasting, Gr 4; etching by plasma technology, Gr 5; etching by hydrofluoric acid ( $\mathrm{n}=7$ ). Microhardness was measured by using Digital Display Vickers Microhardness Tester and flexure strength by using Universal Testing Machine. Results: The results of this study revealed that; Control group of ENA recorded statistically significant highest microhardness. Control group of LVU recorded statistically significant highest flexure strength. Conclusion: Surface treatment has adverse effect on microhardness and flexure strength of both resin ceramic materials.
\end{abstract}

KEY WORDS: Resin ceramics, Microhardness, Flexural strength, Alumina particles, plasma.

\section{INTRODUCTION}

Ceramics are popular dental restorative materials because of their esthetic advantages, good mechanical properties, optical properties, chemical stability and biocompatibility ${ }^{(1)}$.

Though with invent and advancement of material science and processing techniques, newer ceramics are now able to withstand cracks and fracture ${ }^{(2)}$. During the last decade there have been remarkable developments in the application of computer-aided designcomputer-aided milling (CAD-CAM) techniques. This led to high restoration accuracies, reductions in the fabrication cost per unit, and shortening of the time required to fabricate the restoration ${ }^{(3)}$.

Recently, manufacturers have been developing new formulations for chairside CAD/CAM materials composed of two matrices: a polymer and a ceramic networks. This dual network structure reduced brittleness and surface hardness of the material allowing easier milling in a shorter time. The properties of resin-infiltrated ceramics (RIC) make them an interesting choice as interim restorations during management of and rehabilitation of complicated cases ${ }^{(4)}$.

A new hybrid resin ceramic CAD/CAM blocks combine the advantageous properties of ceramics, such as durability and color stability, with those of composite resins, such as improved flexural properties and low abrasiveness ${ }^{(5,6)}$. One of the most important features of hybrid ceramic is that it causes far less wearing out of the antagonist tooth, which is a known disadvantage of feldspathic ceramic, while it also has the advantage of a simple fabrication process because sintering is not required after milling (7).

\footnotetext{
* Assistant lecturer of Dental Bio-Materials Department, Faculty of Dentistry, Assuit, Al-Azhar University.

** Professor and Head of Dental Bio-Materials Department, Faculty of Dentistry, Cairo, Boys, Al-Azhar University. *** Lecturer of Dental Bio-Materials Department, Faculty of Dentistry, Cairo, Boys, Al-Azhar University.
} 
So, hypothesis of this study was done that there will be an effect of different surface treatments on microhardness and flexure strength of both resin ceramic materials

\section{MATERIALS AND METHODS}

In this in-vitro study, two types of CAD/CAM resin ceramic materials (Vita Enamic [ENA] and Lava Ultimate [LVU]) were used. Two properties were measured in this study (microhardness and flexure strength) before and after different surface treatments.

\section{Samples grouping:}

A total number of 140 samples were used in this study (70 samples for each test). The samples were divided into two equal groups according to type of materials (LVU and ENA), then each group was subdivided according to surface treatments into five subgroups Gr 1; no surface treatment (control), Gr 2; alumina particles with size $(50 \mu \mathrm{m})$ for sandblasting, Gr 3; alumina particles with size $(110 \mu \mathrm{m})$ for sandblasting, Gr 4; etching by plasma technology, Gr 5; etching by hydrofluoric acid $(n=7)$.

\section{Samples preparation:}

Materials were sectioned into $1.5 \mathrm{~mm}$ thickness for microhardness test and (4 mm width, $2 \mathrm{~mm}$ thickness, $14 \mathrm{~mm}$ length) for flexure strength test according to (ISO 6872:2008) by using an Isomet Saw (Buehler, Lake Bluff, IL, USA).All samples were wet polished sequentially with 600,800 , and 1000 silicon carbide paper (3M, St. Paul, MN, USA) then rinsed with water ${ }^{(8)}$.

\section{Different surface treatments:}

Sandblasting was performed by airborneabrasion that applied evenly to the surfaces of the samples, by spraying $(50-\mu \mathrm{m} \& 110-\mu \mathrm{m}) \mathrm{Al}_{2} \mathrm{O}_{3}$ particles (Quattro IS, Renfert, Hilzinger, Germany) for 20 second from a distance of $10 \mathrm{~mm}$, at pressures of $0.1 \mathrm{MPa}$ by using sandblasting machine (Sandstorm, Vaniman manufacturing Co, Fallbrook,
California, US $)^{(7)}$. A low vacuum non-thermalplasma chamber (Femto PCCE Zahntechnik, diener electronic $\mathrm{GmbH}$ und Co. KG, Ebhausen, Germany) was used for the plasma treatment. For this purpose, oxygen gas was used as the working gas in the plasma focus system and the condenser bank was charged to $12 \mathrm{kV}$. The energetic oxygen ion beam took the shape of fountain and spread upwards to bombard the facing samples ${ }^{(9)}$. HF gel 9.6\% (Micerium S.B.A. Via G. Italy) was applied to the surface of the samples for $60 \mathrm{~s}$ and rinsed with distilled water for $2 \mathrm{~min}$.

\section{Microhardness test:}

After different surface treatments surface microhardness of the samples was determined using Digital Display Vickers Microhardness Tester (Model HVS-50, Laizhou Huayin Testing Instrument Co., Ltd. China) with a Vickers diamond indenter and a 20X objective lens. A load of $200 \mathrm{~g}$ was applied to the surface of the samples for 20 seconds. Three indentations, which were equally placed over a circle and not closer than $0.5 \mathrm{~mm}$ to the adjacent indentations, were made on the surface of each sample. The diagonals length of the indentations were measured by built in scaled microscope ${ }^{(10)}$.

Microhardness was obtained using the following equation: $\mathrm{HV}=1.854 \mathrm{P} / \mathrm{d}^{2}$

Where, $\mathrm{HV}$ is Vickers hardness in $\mathrm{Kgf} / \mathrm{mm}^{2}$, $\mathrm{P}$ is the load in $\mathrm{Kgf}$ and $\mathrm{d}$ is the length of the diagonals in $\mathrm{mm}$.

\section{Flexure strength test:}

After different surface treatments samples were individually and horizontally mounted in a custom made loading fixture [three point bend test assembly; two parallel stainless steel rods with span length $13 \mathrm{~mm}$ (ISO 6872:2008) supporting the sample, with the damage site centrally located on the tensile side] on a computer controlled materials testing machine (Model 3345; Instron Industrial Products, Norwood,MA, USA) with a load cell of 5 $\mathrm{kN}$ and data were recorded using computer software 
(Instron ${ }^{\circledR}$ Bluehill Lite Software). Then the samples were statically compression loaded until fracture at a crosshead speed of $1 \mathrm{~mm} / \mathrm{min}$. The stress-strain curves were recorded with computer software. Flexure strength represents the limiting stress at which failure or instability is imminent. The value of the calculation of flexure strength was guided by the formula: Flexure strength (ó) $=3 \mathrm{~F}(\mathrm{~L}) / 2 \mathrm{wh}^{2(11)}$.

Where; $\mathrm{F}$ is the maximum load at the point of fracture $(\mathrm{N}), \mathrm{L}$ is the support span $(\mathrm{mm}), \mathrm{w}$ is the width of the sample $(\mathrm{mm})$ and $\mathrm{h}$ its height $(\mathrm{mm})$.

\section{Statistical Analysis}

Independent-samples t-test of significance was used when comparing between two means. A one-way analysis of variance (ANOVA) when comparing between more than two means. Post Hoc test was used for multiple comparisons between different variables.

\section{RESULTS}

\section{Microhardness:}

The comparison between the mean microhardness of the two ceramic materials with and without surface treatments are graphically represented in figure (1).

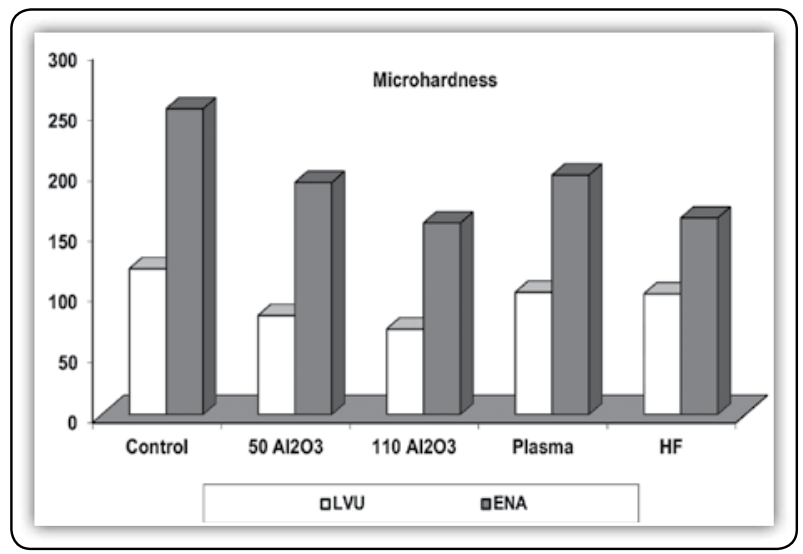

FIG (1) Bar chart of microhardness mean values for both resin ceramics materials as function of different surface treatments.
Control group of ENA recorded statistically significant higher microhardness mean value than LVU. Microhardness decreased when different surface treatments were used. Control group of ENA recorded statistically significant highest microhardness mean value $\left(252.77 \pm 5.30 \mathrm{Kgf} / \mathrm{mm}^{2}\right)$, followed by plasma surface treatment group mean value $\left(198.03 \pm 5.48 \mathrm{Kgf} / \mathrm{mm}^{2}\right)$, then $50 \mu \mathrm{m} \mathrm{Al}_{2} \mathrm{O}_{3}$ surface treatment group mean value $(191.85 \pm 4.89$ $\mathrm{Kgf} / \mathrm{mm}^{2}$ ), then HF surface treatment group mean value $\left(162.47 \pm 2.21 \mathrm{Kgf} / \mathrm{mm}^{2}\right)$, while $110 \mu \mathrm{m} \mathrm{Al}_{2} \mathrm{O}_{3}$ surface treatment group mean value recorded statistically significant lowest microhardness mean value $(158.35 \pm 2.78 \mathrm{Kgf} / \mathrm{mm} 2)$ in all different surface treatments as indicated by ANOVA test followed by pair-wise Tukey's post-hoc test ( $\mathrm{p}<0.05$ ).

Control group of LVU recorded statistically significant highest microhardness mean value (120.67 $\pm 2.009 \mathrm{Kgf} / \mathrm{mm}^{2}$ ) followed by plasma surface treatment group mean value $(101.18 \pm 2.27 \mathrm{Kgf} /$ $\mathrm{mm}^{2}$ ), then HF surface treatment group mean value $\left(99.8267 \pm 3.923 \mathrm{Kgf} / \mathrm{mm}^{2}\right)$, then $50 \mu \mathrm{m} \mathrm{Al}_{2} \mathrm{O}_{3}$ surface treatment group mean value $(81.9333 \pm$ $2.46955 \mathrm{Kgf} / \mathrm{mm}^{2}$ ), while $110 \mu \mathrm{m} \mathrm{Al}_{2} \mathrm{O}_{3}$ group of LVU recorded statistically significant lowest microhardness mean value $\left(70.7667 \pm 088015 \mathrm{Kgf} / \mathrm{mm}^{2}\right)$ in all different surface treatments as indicated by ANOVA test followed by pair-wise Tukey's posthoc test $(\mathrm{p}<0.05)$.

\section{Flexure Strength:}

The comparison between the mean flexure strength of the two ceramic materials with and without surface treatments are graphically represented in figure (2).

Control group of LVU recorded statistically significant higher flexure strength mean value than ENA. The flexure strength decreased when different surface treatments were used. Control group of LVU recorded statistically significant highest flexure strength mean value $(139.84 \pm 10.69 \mathrm{MPa})$, followed by plasma surface treatment group mean 


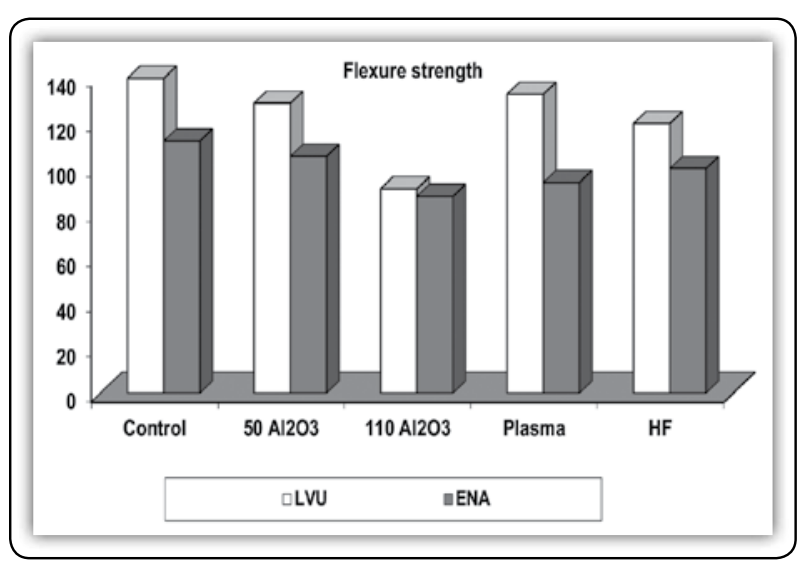

FIG (2) Bar chart of flexure strength mean values for both ceramic materials as function of different surface treatments

value $(132.81 \pm 6.78 \mathrm{MPa})$, then $50 \mu \mathrm{m} \mathrm{Al}_{2} \mathrm{O}_{3}$ surface treatment group mean value $(128.82 \pm 10.75$ $\mathrm{MPa})$, then HF surface treatment group mean value $(119.79 \pm 3.54 \mathrm{MPa})$, while $110 \mu \mathrm{m} \mathrm{Al}_{2} \mathrm{O}_{3}$ surface treatment group mean value recorded statistically significant lowest flexure strength mean value $(90.79 \pm 8.45 \mathrm{MPa})$ in all different surface treatments as indicated by ANOVA test followed by pair-wise Tukey's post-hoc test ( $p<0.05)$. In ENA, control group recorded statistically significant highest flexure strength mean value $(111.99 \pm 5.78 \mathrm{MPa})$ followed by $50 \mu \mathrm{m} \mathrm{Al}_{2} \mathrm{O}_{3}$ surface treatment group mean value $(105.13 \pm 2.55 \mathrm{MPa})$, then HF surface treatment group mean value $(99.68 \pm 9.25 \mathrm{MPa})$, then plasma surface treatment group mean value $(93.40 \pm 8.65 \mathrm{MPa})$, while $\mathrm{Al}_{2} \mathrm{O}_{3} 110 \mu \mathrm{m}$ group of ENA recorded statistically significant lowest flexure strength mean value $(87.59 \pm 7.26 \mathrm{MPa})$ in all different surface treatments as indicated by ANOVA test followed by pair-wise Tukey's post-hoc test ( $\mathrm{p}$ $<0.05)$.

\section{DISCUSSION}

The combination of accurate digital imaging systems combined with state of the art design and milling technology (CAD/CAM) allowed fabrication of all-ceramic restoration with high reliability and success rate. Recently, new resin ceramics $\mathrm{CAD} / \mathrm{CAM}$ blocks were introduced to the dental field, composed of two matrices: a polymer and a ceramic networks ${ }^{(12)}$.

Surface hardness is a key in determining the ease of machining and the degree of chipping during a grinding process, which has a direct impact on the clinical life of the dental restoration. Surface hardness also described as relative measure of resistance to permanent surface indentation. Indentation hardness is defined as a factor that affects the capability of getting finished and polished and also resistance of a material to occlusal wear. Also, resin ceramics are ideally softer than the conventional ceramics, to avoid damage to opposing dentition ${ }^{(13)}$. The Vickers hardness indentation techniques are the most suitable methods for evaluation the hardness of brittle materials (dental ceramics) ${ }^{(14)}$.

The flexural strength measurement can be used to evaluate the resistance of a material to failure from bending. Ceramic materials are brittle and may contain flaws. When the stress is pointed to the material in different directions as in the biaxial three-point bending flexural strength test, more flaws can be situated perpendicular to loading axes compared with the uniaxial tension test. Differences in strength values between the test methods were observed when the three-point-bend test and the biaxial flexural strength test were compared. The three-point bend test gave $20 \%$ to $30 \%$ higher strength values. This might be because not all the strength-limiting flaws were situated perpendicular to the loading axis ${ }^{(15)}$.

The present study found that ENA recorded statistically significant higher microhardness mean values than LVU. ENA seems to have similar wear resistance to glass-ceramics, which contain silica particles. Therefore one could expect that this ENA exhibits relatively good wear performance clinically ${ }^{(16)}$.

This is aggrement with El Zhawi et al ${ }^{(17)}$ whose reported that ENA has a dual-phase microstructure, 
with a dominant feldspathic ceramic network that is interpenetrated by a polymer phase. The use of the dual microstructure with interpenetrating networks also fully capitalizes the advantage of the $\mathrm{CAD} /$ CAM technology.

In the present study, LVU has significantly higher flexural strength than ENA. Although both of these materials contained organic network, there are differences in inorganic content of these two materials: $\mathrm{LVU}$ has $31 \% \mathrm{ZrO}_{2}$ and ENA has $20.6 \%$ $\mathrm{Al}_{2} \mathrm{O}_{3}$ in the inorganic structure ${ }^{(18)}$.

Both LVU and ENA were produced to combine the advantages of ceramics and polymers. Although these materials are classified similarly, they are manufactured differently. ENA material containing a weak glass matrix and irregularly shaped crystalline phases such as silica, potash, and alumina, which are more brittle than the LVU ${ }^{(19)}$.

This aggrement with Sonmez et al ${ }^{(16)}$ whose found that significantly different flexural strength of LVU and ENA may be due to the differences in composition of the resin matrix, dimension, and dispersion of the filler particles. This finding disagreement with Abi et al ${ }^{(20)}$ whose found this difference insignificant which may be due to different test methods and samples dimensions.

Air abrasion decreased microhardness and flexure strength of resin ceramic materials compared with plasma surface treatments. This is due to appearance of surface microcracks and destruction after air abrasion of resin ceramic surfaces. If air borne-particle abrasion is chosen as the surface pretreatment for resin ceramics, grit blasting should be performed with due care. The use of small particles and low pressures is of particular importance, because otherwise surface damage and crack formation may occur ${ }^{(21)}$.

Oxygen plasma was found to produce standard treatment similar to airborne particle abrasion, but without significantly altering surface properties ${ }^{(22)}$.
As shown in present study, plasma treatment did not cause obvious changed in microhardness and flexure strength. HF acid etching for $60 \mathrm{~s}$ decreased microhardness and flexure strength of ENA in comparison with LVU. This is may be due to HF acid dissolves the glassy phase of the ENA and thus changes the microstructure of ceramic surface. This creates micro porosity on the resin ceramic surface $^{(23)}$.

\section{CONCLUSION}

Within the limitations of this study the following conclusions might be drawn:

1. Surface treatments have adverse effect on microhardness and flexure strength of both resin ceramic materials.

2. Sandblasting with $110 \mu \mathrm{m} \mathrm{Al}_{2} \mathrm{O}_{3}$ particles has deteriorating effect on the properties of resin ceramic materials, while plasma had less influence on all tested materials.

\section{REFERENCES}

1. Cekic-Nagas I, Ergun G, Egilmez F, Vallittu PK, Lassila LVJ. Micro-shear bond strength of different resin cements to ceramic/glass-polymer CAD-CAM block materials. J Prosthet Dent. 2016;60(4):265-73.

2. Nathan ASC, Tah R, Balasubramanium MK. Evaluation of fracture toughness of zirconia silica nano-fibres reinforced feldespathic ceramic. J Oral Biol Craniofac.2017; 54(3):244-52

3. Miyazaki T, Hotta Y.CAD/CAM systems available for the fabrication of crown and bridge restorations. Aust Dent $\mathbf{J}$. 2011;56(1):97-106

4. Aboushelib MN, Elsafi MH. Survival of resin infiltrated ceramics under influence of fatigue. Dent Mater J. 2016;32(4):529-34

5. Nguyen JF, Migonney V, Ruse ND, Sadoun M. Resin composite blocks via high-pressure high-temperature polymerization. Dent mater J. 2012;28(5):529-34.

6. Schlichting LH, Maia HP, Baratieri LN, Magne P. Noveldesign ultra-thin CAD/CAM composite resin and ceramic occlusal veneers for the treatment of severe dental erosion. J Prosthet Dent. 2011;105(4):217-26 
7. Kim JE, Kim JH, Shim JS, Roh BD, Shin Y. Effect of air-particle pressures on the surface topography and bond strengths of resin cement to the hybrid ceramics. Dent Mater J. 2017;24(5):284-93.

8. Awada A, Nathanson D. Mechanical properties of resin-ceramic CAD/CAM restorative materials. J Prosthet Dent.2015; 114(4):587-93.

9. El-Shrkawy ZR, El-Hosary MM, Saleh O, Mandour MH. Effect of different surface treatments on bond strength, surface and microscopic structure of zirconia ceramic. F Dent J. 2016;2(1):41-53.

10. Lawson NC, Bansal R, Burgess JO. Wear, strength, modulus and hardness of CAD/CAM restorative materials. Dent Mater J. 2016;32(11):275-83.

11. Choi BJ, Yoon S, Im YW, Lee JH, Jung HJ, Lee HH. Uniaxial/biaxial flexure strengths and elastic properties of resin-composite block materials for CAD/CAM. Dent Mater J. 2019;35(2):389-401

12. Coldea A, Swain MV, Thiel N. Mechanical properties of polymer-infiltrated-ceramic-network materials. Dent Mater J. 2013;29(4):419-26.

13. Flanders LA, Quinn JB, Wilson Jr OC, Lloyd IK. Scratch hardness and chipping of dental ceramics under different environments. Dent Mater J. 2003;19(8):716-24.

14. Cesar PF, Gonzaga CC, Miranda Jr WG, Yoshimura HN. Effect of ion exchange on hardness and fracture toughness of dental porcelains. J Biomed Mater. 2007;83(2):538-45.

15. Hjerppe J, Närhi TO, Vallittu PK, Lassila LV. Surface roughness and the flexural and bend strength of zirconia after different surface treatments. J Prosthet Dent 2016;116(4):577-83 .

16. Sonmez N, Gultekin P, Turp V, Akgungor G, Sen D, Mijiritsky E. Evaluation of five CAD/CAM materials by microstructural characterization and mechanical tests: a comparative in vitro study. BMC oral health. 2018;18(1):5-12

17. El Zhawi H, Kaizer MR, Chughtai A, Moraes RR, Zhang Y. Polymer infiltrated ceramic network structures for resistance to fatigue fracture and wear. Dent Mater $\mathbf{J}$. 2016;32(11):1352-61.

18. Ruse N, Sadoun M. Resin-composite blocks for dental CAD/ CAM applications. J Dent Res. 2014;93(12):1232-44.

19. Sen N, Us YO. Mechanical and optical properties of monolithic CAD-CAM restorative materials. J Prosthet Dent. 2018;119(4):593-9.

20. Abi C, Emrullahog O, Said G. Microstructure and mechanical properties of $\mathrm{MgO}$-stabilized $\mathrm{ZrO} 2-\mathrm{Al} 2 \mathrm{O} 3$ dental composites. J Mech of Bio-mater. 2013;18(12):3-21.

21. Strasser T, Preis V, Behr M, Rosentritt M. Roughness, surface energy, and superficial damages of CAD/CAM materials after surface treatment. Clin Oral Investig J. 2018;22(8):2787-97.

22. Júnior VVBF, Dantas DCB, Bresciani E, Huhtala MFRL. Evaluation of the bond strength and characteristics of zirconia after different surface treatments. J Prosthet Dent. 2018;120(6):955-63

23. Bagheri H, Hooshmand T, Aghajani F. Effect of ceramic surface treatments after machine grinding on the biaxial flexural strength of different CAD/CAM dental ceramics. J Dent Tehran.2015;12(9):621-9. 